Western University Scholarship@Western

Centre for Decision Sciences and Econometrics

Technical Reports

Economics Working Papers Archive

1987

\title{
Inflation and the Timing of Price Changes
}

John McMillan

Victoria Zinde-Walsh

Follow this and additional works at: https://ir.lib.uwo.ca/economicscdse_tr

Part of the Economics Commons

Citation of this paper:

McMillan, John, Victoria Zinde-Walsh. "Inflation and the Timing of Price Changes." Centre for Decision Sciences and Econometrics Technical Reports, 15. London, ON: Department of Economics, University of Western Ontario (1987). 


\title{
THE CENTRE FOR DECISION SCIENCES AND ECONOMETRICS
}

\author{
Inflation \\ and The Timing of Price Changes
}

John McMillan

and

Victoria Zinde-Walsh

\section{TECHNICAL REPORT NO. 15 FEBRUARY 1987}

i

Centre For Decision Sciences And Econometrics Social Science Centre The University of Western Ontario London, Ontario N6A 5C2
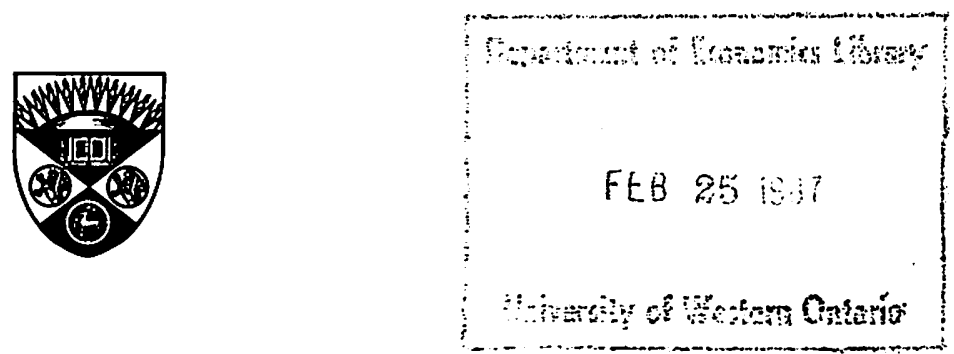
ISSN: $0831-4454$

ISBN : 0-7714-0837-4

INFLATION AND THE TIMING OF PRICE changes*

by

John McMillan

and

Victoria Zinde-Walsh

University of Western Ontario

Revised: January 1987

\begin{abstract}
Consider an oligopolistic industry in which the firms produce perfect substitutes and incur transaction costs of changing price. Under constant inflation, there is an equilibrium in which the firms change their nominal prices at equally spaced time-points. Increasing the inflation rate increases the size of price changes, increases the frequency of price changes, and increases the average real price paid by buyers. 'lihe analysis derives its significance from its implications for the welfare costs of inflation: the inflation-induced distortions in relative prices are larger the more sticky nominal prices are; and are larger the greater the tendency for firuns to stagger (rather than synchronize) their price changes.
\end{abstract}

Correspondence to: V. Zinde-Walsh

Department of Economics

University of Western Ontario

London, Ontario N6A $5 \mathrm{C2}$

Canada 


\section{Introduction}

Can perfectly anticipated inflation be harmful? If inflation distorts relative prices and thereby inhibits the allocative cole of the price system, it causes welfare losses. This occurs if nominal prices are sticky ${ }^{1}$ and different firms change their nominal prices at different points in time (Laidler, 1978; Parkin and Swoboda, 1978). The welfare loss from anticipated inflation, therefore, is likely to be larger the more sticky are nominal prices; and it is likely to be larger or smaller depending on whether there is a tendency for firms within an industry to stagger or to synchronize their price changes. This paper addresses the question of whether it is in firms' interests to stagger their nominal price changes in the face of a predictable inflation rate. The model identifies some sources of welfare loss from anticipated inflation.

Several rational-expectations macroeconomic models postulate temporary rigidities of prices and wages. Once it is admitted that prices do not respond instantaneously to changed economic circumstances, the question of the timing of price changes becomes important: by imposing certain assumptions about timing, some Keynesian flavor is introduced into rational-expectations models. The macroeconomic significance of timing is illustrated by the models of Fischer (1977), Phelps (1978), and Taylor (1980, 1981). Fischer and Phelps showed that the stickiness of prices means that correctly perceived but unanticipated monetary policy can have real effects. Taylor's model postulates an overlapping structure of price decisions. In each period, some fitms can change their prices, while the other firms must continue to charge the same prices as in the previous period: inflationary inertia (and quantity inertia) is generated by the dependence of current optimal prices on prices which were set in the past but are still in effect. 
The results of the Fischer, Phelps, and Taylor models depend crucially on the time structure of the agents' decisions; both the extent of synchronization of the different firms' decisions and the length of time for which nominal prices are held constant are given exogenously in these models. As Lucas noted: "None of the models offers an explanation as to why people should choose to bind themselves to contracts which seem to be in no one's self-interest" (Lucas, 1981, p. 564). This paper develops some microeconomic foundations for such models by making both the degree of price stickiness and the timing of price changes the outcome of the firins optimizing decisions. 2

In the model of Iaylor $(1980,1981)$ the assumed time structure is that each firm's nominal price, once set, is held constant for N periods; a fraction $1 / N$ of the firms set their prices at the beginning of each period. If $N$ is the number of firms, these price changes are uniformly distributed over time. An alternative symnetric time pattern has all firms changing their prices simultaneously: if this were the equilibrium, the inertia identified by Taylor would not exist. This paper addresses the question of whether either of these patterns of price change could be the result of rational. tinning decisions by the firms. ${ }^{3}$

The following formulation presents a solution to a game-theoretic problem in which the timing of actions is one of the strategic variables. What emerges is in effect a discrete-time model in which the discreteness is endogenous: the underlying framework is in continuous time but, by the agents' choices, actions occur only at equally spaced points in time. Discrete-time dynamic models of oligopoly often impose a particular time slructure on the firms' moves: either simultaneous (for example, Friedman, 1977), or alternating (Cyert and de Groot, 1970). Other models allow the choice between simultaneous and alternating moves to be made by the firms 
(Maskin and Tirole, 1982). All of these are special cases of a continuous-time model in which not only the sequence of moves, but also the duration of the time interval between actions are chosen by the firms: an example of such a model is developed in this paper.

Our model has multiple Nash equilibria, none of which is subgame perfect. To overcome the multiplicity problem we propose an additional equilibrium criterion, robustness, which requires that the strategies used never call for a drastic response to a small deviation by another player: thus robust equilibria are not destroyed by small miscalculations by the players or small random shocks in the environment. Robustness allows us to focus on a particular Nash equilibrium, in which the firms stagger their nominal-price changes .

\section{Transaction Costs}

After noting that his model "does not provide a microeconomic basis for the existence of long-tern nominal contracts", Fischer suggested that "the transaction costs of frequent price setting and wage negotiations must be part of the explanation" (Fischer, 1977, p. 194). This paper elaborates on that suggestion.

Consider a firm operating in an inflationary environment; inflation is constant and predictable. If this firm were a textbook nonopolist, its nominal price would simply track the general price level. Suppose, inslead, that the firm incurs a transaction cost whenever it changes its nominal price. The size of this transaction cost is assumed for simplicity to be constant, regardless of the size of the price change. Then, as Sheshinski and Weiss (1977) showed, the firm's nominal price, rather than continuously changing, follows a pattern of being constant for some length of time and then increasing in a discrete jump. ${ }^{4}$ 
In this paper, the Sheshinski-Weiss monopoly analysis is extended to a market containing several firms competing with each other. This adds a new dimension to the conventional oligopoly problem: in addition to using price as a strategic variable, the firms strategically choose the timing of their price changes.

It might be suggested, in criticism of the present approach, that transaction costs of changing price are likely to be small in practice, and therefore that phenomena generated by transaction costs are likely to be of little empirical significance. Three responses may be made.

First, the analysis to be developed applies for any non-zero level of the transaction cost; the existence of any transaction cost, no matter how sinal.1, will result in staggered price changes and some degree of price stickiness. Second, Blanchard (1982) showed that interactions across different industries can generate substantial aggregate price-level stickiness even if individual firms hold their nominal prices constant for relalively shorl periods of time. Thus small transaction costs may have significant general-equilibrium consequences.

Third, it is not obvious on a priori grounds that these transaction costs are, in fact, small. The transaction cost incurred on changing nominal price can be interpreted in two ways. It can be interpreted literally as a cost of changing price. It has been argued that such costs are of significance in practice: "One of the major stumbling blocks to swift action in many companies is adninistrative procedures. Price increases are a complex exercise for many companies, in many cases involving a change of price lists, notification to customers and salesmen, and changing computer data so that invoices are issued at the appropriate rates. Only the customers and 
salesmen like price increases less than the administrative staff involved in making these changes. Where catalogues and sales literature are involved, price alterations may be expensive" (Hussey, 1976, pp. 83-84). Alternatively, the transaction cost may be interpreted less directly as being a proxy fur losses incurred as a result of various kinds of informational problems (although uncertainty is not incorporated in this model): the loss in profits if some regular customers, as a result of the nominal price change, decide to shop elsewhere (Stiglitz, 1979; McMillan and Morgan, 1986), or the risk that the firm will lose profits by mistaking a temporary demand change for a permanent one and changing price when no price change is warranted (Kawasaki, McMillan, and Zimnermann, 1983). The reason for simply assuming the existence of a transaction cost, rather than modelling in detail the sources of the transaction cost, is that this paper focuses on the timing of price changes; the, focus is not on the question of why prices are sticky. Postulating a transaction cost of changing nominal price provides a simple and direct way of making stickiness of nominal prices the outcome of firms' optimizing decisions. One way of reducing the total cost of changing prices, given the assumed predictable nature of inflation, might be for a firm to quote, not a nominal price, but a nominal-price function, linking nominal price to the inflation rate. Since, realistically, firms of ten do not do this (perhaps because it involves other kinds of costs), we assume firms must quote prices, not price functions. (That is, the institutional setting is such that money is the unit of account: Hussa (1977); Laidler (1978).) 


\section{Definitions and Assumptions}

The model is partial equilibrium, a multi-firm generalization of the monopoly model of Sheshinski and Weiss (1977). Consider an industry containing $k$ identical firms. Inflation occurs at the constant rate $8>0$. Denote by $q^{i}$ the nominal price charged by firm $i$ and by $z_{t}^{i} \equiv q^{i} e^{-g t}$ the real price of $f i r m ~ i$ at time $t$. Let $w_{t}^{i}$ denote the logarithm of a real price, $w_{t}^{i}=\ln z_{t}^{i}$, and let $p^{i}=\ln q^{i}$, so that $w_{t}^{i}=p^{i}-g t$. For the sake of convenience, the $w_{t}^{i}$ 's will be referred to as "real prices" and the $p_{t}^{i}$ 's as "nominal prices". Let $w_{t}=\left(w_{t}^{1}, \ldots, w_{t}^{k}\right)$ be the $k$-vector of real prices and $w_{t}^{-i}$ be the $(k-1)$-vector of real prices with the price of firm $i$ excluded. Nominal-price vectors $p$ and $p^{-i}$ are defined similarly.

Assumption 1: The firms produce homogeneous products.

Because of the homogeneity assumption, the firm charging the lowest price captures the entire market. (The homogeneity assumption is somewhat unsatisfactory, as it implies a sudden switching of all buyer's from one seller to another following one seller's price change.)

With homogeneous products, there must be some tie-breaking rule for the case in which two or more firuns charge the same price; the simplest is as follows.

Assumption 2: With in firms charging the same lowest price, the market is shared equally among the $m$ firms.

Given the real price vector $w_{t}$, the profit of $f i r m ~ i$ is given by

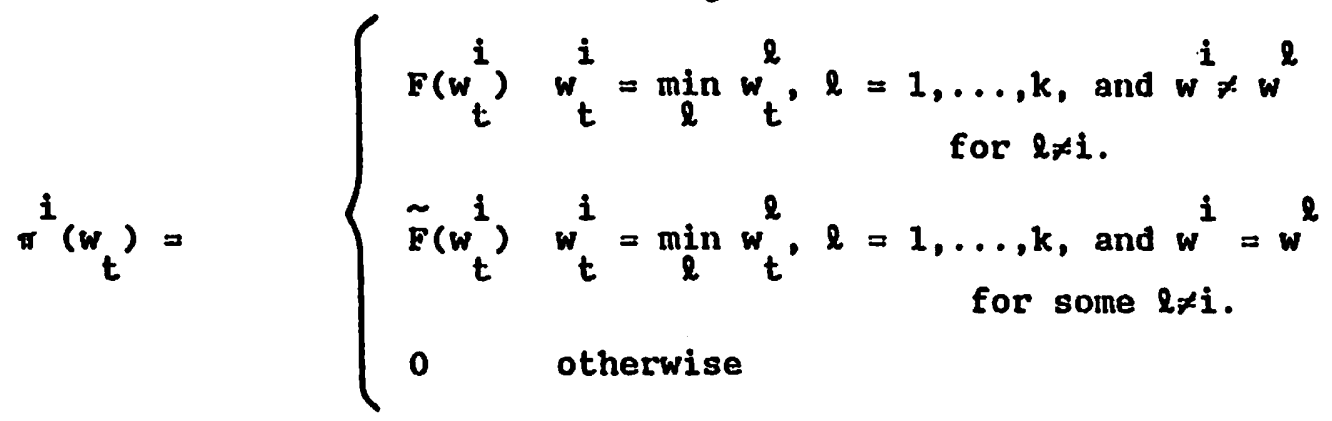


where $F\left(w_{t}^{i}\right), \tilde{F}\left(w_{t}^{i}\right)$ represent instantaneous profits at price $w_{t}^{i}$, and $F\left(w_{t}^{i}\right)>\tilde{F}\left(w_{t}^{i}\right)$. Thus firm i's profit is a function only of its own price and the lowest of its rivals' prices. The functions $F$ and $\tilde{F}$ are assumed to be measurable.

Following Sheshinski and Weiss (1977), assume that changing nominal price is costly.

Assumption 3: Any change in nominal price entails a real cost of $\beta>0$ to the firm.

The positive real cost of changing nominal price clearly means that in equilibrium nominal prices cannot change continuously; instead, a nominal price, when it changes, will increase by a discrete amount and then be held constant for some time interval. Suppose the firm $i$ changes its nominal price al the time-points $t_{n}^{i}, n=0,1, \ldots$ with $t_{0}^{i}<t_{1}^{i}<\ldots$. Within the interval $\left(t_{n}^{i}, t_{n+1}^{i}\right)$, the $f$ irm's nominal price is held constant at $p_{n}^{i}$. Hence its real price declines over this interval: for $t_{n}^{i} \leq t<t_{n+1}^{i}$, firm i's real price is $w_{t}^{i}=p_{n}^{i}-g t$.

Consider a firm charging at some time $t$ a nominal price $p$ below all the other firms' prices. Take the initial time-point to be $t=0$ and denote the initial real price by $w_{0}$. Suppose that until the firm changes its price it remains the lowest price. Then the net profits earned by the firm discounted with rate $r$ over this interval (including the moment of price change) can be expressed as

(2) $\int_{0}^{T} F(p-g t) e^{-r t} d t-\beta e^{-r T}$, 
or equivalently, by substituting $w=p-g t, w_{T}=p-g T$,

(3) $\frac{1}{8} \int_{w_{T}}^{w_{0}} F(w) e^{\left.-\frac{r}{g} w_{0}-w\right)} d w-\beta e^{\left.-\frac{r}{g} w_{0}-w_{T}\right)}$.

Note that $w_{0}>w_{\mathrm{T}}$ since the real price decreases with inflation for a fixed nominal price.

Assumption 4: For given $g, r$ and $\beta$ there exists $w_{0}$ such that for some $w_{T}<w_{0}$ the expression $(3)$ is non-negative.

If the inflation rate $g$ is too large given the cost of price change $\beta$ (or if the cost of price change is too large given the inflation rate), it will not be possible for a firm to earn non-negative profits in equilibrium. Assumption 4 implies that $g$ and $\beta$ are such that non-negative profits are attainable.

Assumption 5: There exists $w_{0}$ such that for any $w_{T}<w_{0}$ the expression (3) is negative.

This assumption says that after attaining some low real price a firm would lose more than the cost of price change if it continued with its current nominal price, supposing, of course, that its price is the lowest. Denote by $p_{0}$ the upper bound of all $w_{0}$ which satisfy Assumption 5 .

Because of Assumption $4, p_{0}$ is finite. Since the integral and the exponent in (3), are continuous functions of $w_{0}, w_{1}$, for $w_{0}=p_{0}$ there exisls an $x_{0}$ such that for $w_{T}=x_{0}$ (3) equals zero. This price $x_{0}$ provides a lower bound on the real prices which a firm would wish to charge. Indecd, consider continuing past $x_{0}$. If one started at $p_{0}$, going past $x_{0}$ means earning negative rather than zero profits. This implies that 
(4) $\frac{1}{g} \int_{x_{0}-x}^{x_{0}} F(w) e^{\frac{F}{g}} d w-\beta\left(e^{-\frac{r}{g}} e^{-\left(x_{0}-x\right)} e^{\frac{r}{g^{-x}}}\right)<0$ for any $x>0$.

But the left-hand side of (4) is proportionate (up to $\exp \left\{-\mathrm{r}_{0} / \mathrm{B}\right\}$ ) to the difference between the profit earned starting with any $w_{0}>x_{0}$ (rather than $P_{0}$ ) and continuing to $x_{0}$ and the profits between $w_{0}$ and $x_{0}-x$. Since this difference is always negative, continuing past $x_{0}$ is never profitable.

We shall also require that the firms will not set their prices in such a way that the corresponding real prices are arbitrarily high.

Assumption 6: The expression in (3) attains its maximum value $M<\infty$ for some $w_{0}, w_{T}<w_{0}$ with $w_{0}<c<\infty$.

We can therefore restrict the real prices to a compact subset $B^{i} C R$ for

firm $i$. The set $B^{i}$ is bounded from below by $x_{0}$. Denote $B=\prod_{i=1}^{k} B^{i}$ and assume that $w \in B$.

Assumption 7: For any $w_{T}$ such that $x_{0}<w_{T}<c$ there exists $c>0$ such that, for any $0<x<\varepsilon$,

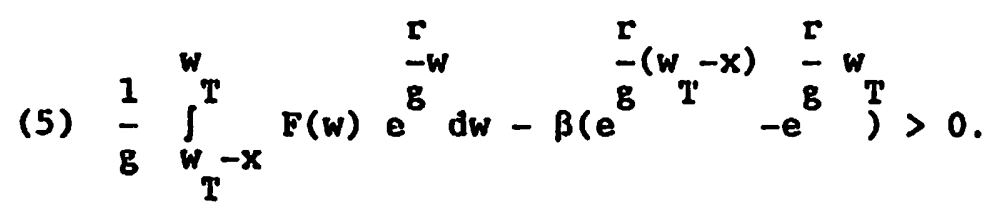

This assumption provides some regularity in the profit function by not allowing it to dip down to too low negative values before reaching $x_{0}$. Suppose that $F$ is continuous. Then (5) is equivalent to $F^{\prime}\left(w_{T^{\prime}}\right)>-r \beta$ for $x_{0}<w_{T}<C$ (note that $F\left(x_{0}\right)$ then equals $-r \beta$ ). 
A price path $w^{i}(t)$ of $f i r m ~ i$ is given by a sequence of nominal prices and times of price changes $\left\{p_{n}^{i}, t_{n}^{i}\right\}$ with (6) $w^{i}(t)=p_{n}^{i}-$ gt for $t_{n}^{i} \leq t<t_{n+1}^{i}$. Denote by $w(t)$ the vector $\left(w^{1}(t), \ldots, w^{k}(t)\right)$. This definition of a price path implies semi-continuity, since $t_{n}^{i} \neq t_{n+1}^{i}$ otherwise $w^{i}(t)$ is not unambiguously defined at $t=t_{n}^{i}$. It follows that along a price path the limit from the left: (7) $w_{\ell}(t)=\lim _{\substack{s \rightarrow 0 \\ s>0}} w(t-s)$

always exists.

The total discounted profits of firm $i$ along a price path $w(t)$ (starting with some price vector $w_{0}$ ) depend on the price paths of all the firms

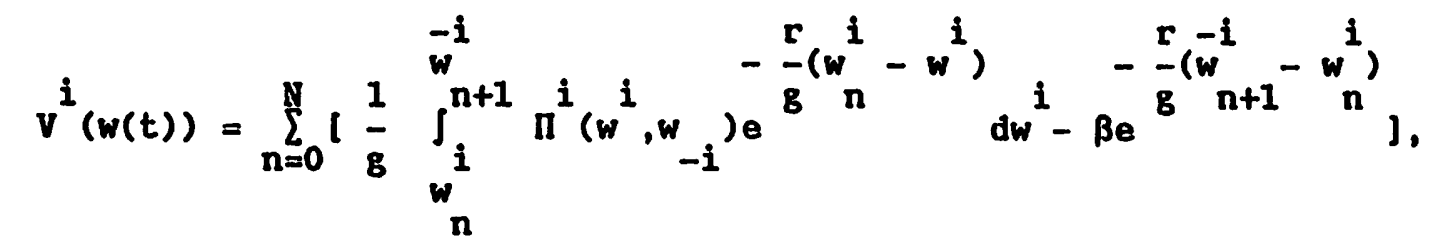
where $w_{n}^{i}=w^{i}\left(t_{n}^{i}\right), w_{n}^{-i}=w_{\ell}^{i}\left(t_{n}^{i}\right)$, with $w_{\ell}^{i}$ defined by $(7) . \quad$ In $(8), w$ could be infinity or a finite integer. Note that Assumption 6 guarantees that (8) is bounded from above.

\section{Strategy Sets}

Equilibria of dymamic games may be either open-loop or closed-loop. In an open-loop equilibrium, strategies are functions of time alone. In the present model, if one firm were to adopt an open-loop strategy, committing its price to follow a fixed time-path, its rivals could slightly undercut its price over some time-intervals, thereby obtaining. the whole market. That is, it would be in the rivals' interest to adopt a strategy which is a function of the current 
price vector as well as time. Thus there is no open-loop equilibrium in this model. We consider therefore closed-loop strategies.

We introduce several sets whose elements are price-paths or vectors of price-paths satisfying (6) and thus (7) as well. Denote by $P_{i}(T)$ the set of price paths of firm $i, w^{i}(t)$, which satisfy (6) for $0 \leq t<T$. Denote by $P(I)$ the set of vectors of price-paths from $P^{i}(T), i=1, \ldots, k$. For $\bar{w}(t) \in P\left(T^{\prime}\right)$ and $T>T^{\prime}$, denote by $P(\bar{w}(t), T)$ the set of paths $W(t)$ over $0 \leq t<T$ such that $w(t)=\bar{w}(t)$ for $0 \leq t<T^{\prime}$, thus $P(\bar{w}(t), T)$ includes all price paths with an identical history, $\bar{w}(t)$, up to $T^{\prime}$. If it is not inportant to specify the price-path set we denote it by $P$.

The formula (8) can be used to evaluate the profits over any finite path for any firm:

(9) $V^{i}: P(T) \rightarrow R$,

with $v^{i}(w(t))$ calculated according to (8). The values could diverge to - as $r \rightarrow \infty$.

The strategies of the firms are real price decisions (with correspondingly set nominal prices) for any point in time:

(10) $s_{T}^{i}: \quad P(T) \rightarrow B^{i}$.

Thus, in response to an observed history up to but not including the present moment $T$ the firm strategically chooses its price. Denote by $s_{T}$ the vector $\left(s_{T}^{1}, \ldots, s_{T}^{k}\right)$. For any path $w(t)$ in $P(T)$ and for $T^{\prime}<T$, denote by $\left.w(t)\right|_{T^{\prime}}$ the path in $P\left(T^{\prime}\right)$ which coincides with $w(t)$ for $0 \leq t<T^{\prime}$. 
We say that a path $w(t) c P(\eta)$ is strategy consistent if (11)

$$
s_{T}^{i}\left(\left.w(t)\right|_{T^{\prime}}\right)=w^{i}\left(T^{\prime}\right) \text { for all } T^{\prime}<T, i=1, \ldots, k \text {. }
$$

For a strategy vector 8 , denote by $\mathbf{P}_{\mathbf{s}}\left(T^{\prime}\right)$ the subset of strategy-consistent paths in $P(T)$.

A strategy vector $s$ is consistent if, for any $\bar{w}^{-}(t) \in P\left(I^{\prime}\right)$ and any $I^{\prime}>T^{\prime}$, the set of strategy-consistent paths with the history $\bar{w}(t), P_{s}(\bar{w}, Y)$, is is nonempty. Note that if $P_{8}(\bar{w}, T)$ is nonempty it consists of a single element; therefore, given any price path wich represents the price history of the market, the strategy-consistent path which follows this history is uniquely defined.

Along a consistent path, for any $\bar{w}(t) \in P\left(T^{\prime}\right)$, there exisls $x>0$ such that

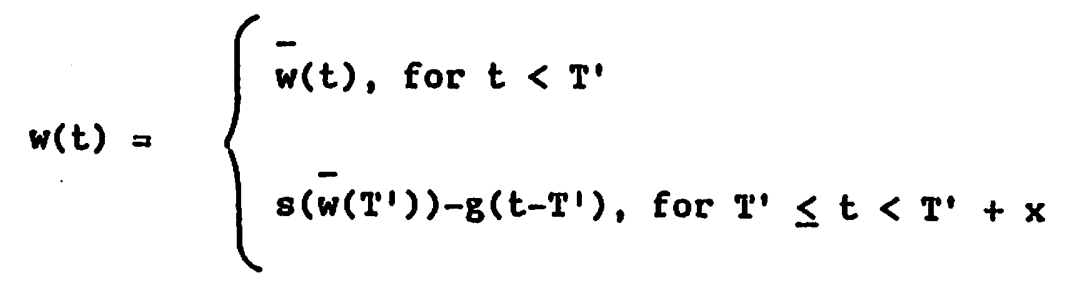

and

$$
s_{T^{\prime}+y}(w(t))=w\left(T^{\prime}+y\right) \text { for any } y<x .
$$

This property imnediately follows from (6) and the definition of consistency. Suppose that $s=\left(s^{1}, \ldots, s^{k}\right)$ is such that, for any $\bar{w}(t) \in P\left(T^{\prime}\right)$ and $Y^{\prime}>T^{\prime}$, the set consisting of paths $w(t) \in P(\bar{w}, T)$, each of which is consistent with every $s^{j}, j \neq i$, is nonempty. Denote by $\left(s^{-i}, h^{i}\right)$ the slrategy vector oblained from $s$ by replacing $s^{i}$ by $h^{i}$. Then there exists $h^{i}$ such that $\left(s^{-i}, h^{i}\right)$ is a consistent strategy vector. One example of such an $h^{i}$ is the stcategy which does not change the nominal price unless $x_{0}$ becomes the limit 
of firm i's prices along the price path. In that case firm i raises its price to a point where it hits a path consistent with the strategies of the other firms.

We introduce a topology on the set of consistent strategy vectors, and close the set in the induced topology. Consider the $L^{1}$ norm on the vector functions $P(T)$ (which have their values in the compact set $B$ ). This norm determines convergence almost everywhere. Denote by $d_{T}(x(t), y(t))$ the distance between any two paths $x(t), y(t)$ in $P(T)$ under this norm. Suppose that $s_{1}$ and $s_{2}$ are two consistent strategy vectors. For any history $\bar{w}(t) \in P\left(T^{\prime}\right)$, with $T^{\prime}<T$, denote by $w_{j}(\bar{w}, T)$ the unique path from $P_{\mathbf{s}}(\bar{w}, T)$ for $j=1,2$. The value of $v^{i}\left(w_{j}(\bar{w}, Y)\right)$ can be calculated using (8) along the path $w_{j}(\bar{w}, T)$. Define

(14) $\mathrm{d}_{\bar{w}, T}\left(s_{1}, s_{2}\right)=\mathrm{d}_{T}\left(w_{1}(\bar{w}, T), w_{2}(\bar{w}, T)\right)+\max _{i}\left|v^{i}\left(w_{1}(\bar{w}, T)\right)-v^{i}\left(w_{2}(\bar{w}, T)\right)\right|$. Consider a sequence $\left\{s_{m}\right\}$ of consistent strategies such that, for any $c>0, \bar{w}, T$, there exists an integer $N$ such that $d_{-}\left(s_{m}, s\right)<\varepsilon$ for any $m, n>N$. It is easy to see that for this sequence $\lim _{\mathfrak{m} \rightarrow \infty} s_{m}^{i}$ is uniquely defined for any $\bar{w}\left(P\left(I^{\prime}\right)\right.$. Therefore, this sequence defines a limit strategy vector $s$ with $s^{i}(w(t))=\lim s_{m}^{i}(w(t))$ for any path $w(t)$. The values $\left.v^{i}(w, \bar{w}, T)\right)$ converge as $m \rightarrow \infty$. We can therefore associate with $s, \bar{w}, T$ payoffs $v^{i}(s, \bar{w}(t), T)=\lim _{m \rightarrow \infty} v^{i}(w(w, T))$, for every $i=1, \ldots, k$. 
Thus (14) defines such a topology on the set of consistent strategy vectors that the closure of this set is, firstly, a subset of the set of strategy vectors, and secondly, a subset on which the payoff functionals $v^{i}$ are defined. Denote this subset by $Q$. For any $s \in Q$ denote by $Q\left(s^{-i}\right)$ the set of strategies $h^{i}$ such that the strategy vector $\left(s^{-i}, h^{i}\right) \in Q$.

We have so far not discussed the cost the firm incurs on changing its nominal price. Since every change in nominal price is necessarily accompanied by a payment of $\beta$, while nothing prevents a firm from paying yet keeping the same nominal price, we can assume that, at the moment when the firm changes its price, two consecutive events occur: a paynent of $\beta$, then the setting of a nominal price.

A strategy vector $s^{*} \in Q$ is an equilibrium if, for each $i=1, \ldots, k$ and any price history $\bar{w}(t) \in P\left(T^{\prime}\right)$ ending with firm $i$ paying $\beta$ at $T^{\prime}$, for all $\mathbf{T}>\mathbf{T}^{\prime}$,

(15) $\left.v^{i}\left(s^{*}, \bar{w}, T\right) \geq v^{i}\left(\left(s^{*-i}, h^{i}\right), \bar{w}, T\right)\right)$

for any $h^{i} \in Q\left(s^{*-i}\right)$.

\section{Myopic strategies}

In general, a large amount of information is required by the fitm in making a decision, since it depends upon the entire hislory of prices. The following proposition shows that it may not be necessary for a firm to use this information if none of the firn's rivals use it. Suppose that a strategy $s^{i}$ of firm $i$ is such that, for any two paths $\bar{w}(t), \bar{u}(t) \in \bar{P}\left(T^{\prime}\right)$ 
with $\bar{w}_{\ell}(T)=\bar{u}_{\ell}(T)$ (where the subscript $\ell$ refers to the limit value defined by $(7)), s_{T}^{i}(w(t))=s_{T}^{i}(\bar{u}(t))$. Then we call the strategy $s^{i}$ myopic. Such a strategy takes into account only the prices that ruled an instant before, and disregards the history that led to these prices.

Proposition 1: Suppose that, in the strategy vector $s=\left(s^{1}, \ldots, s^{k}\right) \in Q, a l 1$ $s^{j}, j \neq i$, are myopic. Then the set of best replies to $s$ by firm $i$ includes $a$ myopic strategy.

Proof: It is sufficient to prove the Proposition for consistent strategies. Suppose that two histories $\bar{w}_{1}(t), \bar{w}_{2}(t) \in P\left(T^{\prime}\right)$ end in firm $i$ paying $\beta$ to change its price at $T^{\prime}$, and that

$$
\bar{w}_{12}\left(T^{\prime}\right)=\bar{w}_{22}\left(T^{\prime}\right)
$$

(here the subscript $\&$ refers to taking the limit according to (7)). Assume that all the ficms except firm i follow myopic strategies but

$$
s^{i}\left(\bar{w}_{1}(t)\right) \neq s^{i}\left(\bar{w}_{2}(t)\right) \text {. }
$$

Then we can assume that for $T>T$ '

$$
v^{i}\left(s, \bar{w}_{1}, T\right)-v^{i}\left(\bar{w}_{1}(t)\right) \geq v^{i}\left(s, \bar{w}_{2}, T\right)-v^{i}\left(\bar{w}_{2}(t)\right) .
$$


Consider a strategy $\stackrel{\sim i}{s}$ for firm $i$ such that, for any strategy-consistent path $w_{2}(t) \in p_{s}\left(\bar{w}_{2}, T\right)$, it replies as if it were $w_{1}(t) \in P_{s}\left(\bar{w}_{1}, T\right)$, that is, $\tilde{s}_{2}^{i}\left(w_{2}(t)\right)=s^{i}\left(w_{1}(t)\right)$; for any other path $\tilde{s}^{i}=s^{i}$. Since all the other strategies are myopic they do not take into account the previous path (do not distinguish $\bar{w}_{2}$ and $\left.\bar{w}_{1}\right)$, therefore $\left(s^{-i}, \sim^{i}\right)$ is a consistent strategy vector and

$$
v^{i}\left(\left(s^{-i}, s^{i}\right), \bar{w}_{2}, T\right)=v^{i}\left(\left(s^{-i}, s^{i}\right), \bar{w}_{1}, T\right)
$$

Thus substituting the strategy $\tilde{s}^{i}$ for $s^{i}$ can only improve the payoffs for firm i. But $\tilde{s}^{i}\left(\bar{w}_{2}\right)=\sim_{s}^{i}\left(\bar{w}_{1}\right)$ as long as $\bar{w}_{2 l}\left(T^{\prime}\right)=\bar{w}_{12}\left(T^{\prime}\right)$.

$$
\text { Q.E.D. }
$$

Thus if all the firms except one follow myopic strategies then it will not benefit the remaining firm to select a more complex strategy. (Compare with the "state-space" strategies of Fudenberg and Tirole (1986)).

For the rest of this paper, we restrict attention to equilibria in myopic strategies.

\section{Equilibria}

In this section, we characterize two types of synunetric equilibria for the price-change game. 
Suppose $s^{\star}$ is an equilibrium strategy vector (we can assume it is consistent). If $s^{*}$ is myopic then each component $s^{* i}$ defines a mapping $s^{\star i}: \quad B \rightarrow B^{i}$, which maps any $w \in B$ onto a strategy-consistent path. Suppose that $w \in B$ is such that $s^{* i}(w) \neq w^{i}$. Then we say that $w$ is an action point for $i$; denote by $A^{i} C$ b the set of all action points for firm $i$.

If $w \in B$ is such that its $i^{\text {th }}$ component $w^{i}$ is equal to $x_{0}$ (defined above following Assumption 5 ), then $w \in A^{i}$. There are two possibilities for this $w$. Either $w \in \Lambda^{j}$ for some $j \neq i$, so that some other firm besides $i$ changes its price upon observing the price vector $w$; or $i$ is the only firm to change its price at $w$. In this last case, a strategy-consistent path passes through a point with all the coordinates except the $i^{\text {th }}$ equal to the respective coordinates of $w$.

Suppose that on a strategy-consistent path firm $i$ alone changes its price from the lowest $w^{i}$ in the price vector $w$ to a price above that of sume firm $j$. Then either $w^{i}=x_{0}$, or $s^{j}(w-g x)<w^{i}-g x$ for any small $x>$ 0. Indeed, assuming $w^{i} \neq x_{0}$ suppose that there exists $\varepsilon>0$ such that, for any $x<c$ and all $j \not i, s^{j}(w-g x)>w^{i}-g x$. Then firm $i$ could delay its price change and after this delay at worst would join the same price path. Its gain would then be proportional to (5), thus positive, contradicting the optimality of the equilibrium strategy.

Thus for a stationary consistent equilibrium only three possibilities can be realized:

(a). several firms change prices simultaneously; 
(b). a firm does not change its price unilaterally unless its price has reached $x_{0}$;

(c). fbr any price vector $w \in A^{i}$ which does not belong to any $A^{j}$ with $j \neq i$ (i.e. where firm $i$ changes its price unilaterally) if $w^{i}>x_{0}$, there exists a strategy consistent path which passes through a point

w with ${ }^{a} j<w^{i}$ for some $j \neq i$ and ${ }^{a} i=w^{i}$.

Assume the instantaneous profit function $F$ to be continuous. Also, for ease of notation, assume there are only two firms (the results clearly also apply to the case of more than two firms).

We consider first an equilibrium which can, for obvious reasons, be called the "price-matching" equilibrium.

Denote by $\tilde{v}(a, b)$ the value of the expression (3) evaluated for $\tilde{F}$ between $a$ and $b$ as the lower and upper prices, respectively, and by $v(a, b) a$ similar expression for $F$.

Proposition 2: Suppose that the prices $a$ and $b$ are such that

$$
\begin{aligned}
& \text { (16) } \tilde{v}(a, b) \geq 0 ; \\
& \text { (17) } \tilde{v}(a, b)>\tilde{v}(a, c) e^{r(b-c)} \text { for } a<c<b ; \\
& \text { (18) } v(a-d, a)-\tilde{v}(b-d, b)+\beta\left(1-e^{-\frac{d}{g}}\right)<0 \text {, for any } d<b-a \text {; } \\
& \text { (19) } \tilde{F}(x)>0 \text { for } x>a .
\end{aligned}
$$


Then the strategies $s^{* 1}, s^{\star 2}$ with

(20) $s^{* i}(w)= \begin{cases}w^{i} & \text { if } b \geq w^{i}=\min \left(w^{1}, w^{2}\right)>a, \\ \min \left(w^{1}, w^{2}\right) & \text { if } b \geq w^{i}>\min \left(w^{1}, w^{2}\right)>a, \\ b & \text { otherwise }\end{cases}$

for $i=1,2$ form an equilibrium.

Proof: We have to show that no change in strategy by one firm could improve its payoff. We need concern ouselves with the following situations only:

(a). upon reaching price a together, one of the firms delays by changing its price, then joins the other price;

(b). a firm raises its price before the other from the joint path;

(c). from the price above the other firm's (and above a) the firm continues rather than joining the lower price;

(d). a firm changes its price along the joint path simultaneously with the other but instead of going to $b$ undercuts it by going to $b-\varepsilon$.

For (a), delaying the price changed from shared level a even momentarily cannot be profitable because of (18), since the left-hand side of (18) represents the gain from such a delay. Because of (19) (b) cannot be profitable since the momentary gain is $\tilde{F}(a)-\beta r$ and is clearly negative. Once a payment was made, joining the lower price is more profitable than continuing since the momentary gain (after the history ending in paying $\beta$ ) is $\tilde{F}(x)>0$ for $x>$ a rather than zero, therefore (c) is not profitable.

Finally for (d) we note that the situation described in it cannot be a part of a consistent strategy. Consider consistent strategies for the rival 
firm allowing (d) to persist for some small amount of time during which a real price declines by $\delta$, otherwise the strategy coincides with that prescribed by (20). If $\delta \rightarrow 0$, that consistent strategy vector would approach one with the designated firm going to $b-c$ instead of $b$ and being joined imnediately by the other. The gain from (d) would then be proportionate to

$$
\tilde{v}(b-c, e) e^{r c}-\tilde{v}(b, a),
$$

which is negative by (17).

$$
\text { Q.E.D. }
$$

The equilibrium of Proposition 2 is somewhat similar to the "matching" equilibrium of Anderson (1985), but, contrary to Anderson's, this equilibrium is not "grim", since here a deviation from the joint path is followed by a return to the equilibrium path. The dynamic nature of the solution (that is, a path of changing prices rather than a single price) allows for this distinction. A "grim" equilibrium, however, is also possible. An equilibrium strategy pair could punish deviations from the equilibriut path by going to a path where each firm earns non-positive profits with staggerod price changes. An equilibrium involving such paths will be presented in Proposition 3.

Note that the existence requirements of Proposition 2 are quite stringent. In particular the number of the firms has to be limited from above in order for the prices, $a, b$, satisfying Proposition 2 to exist. Too many

firns in the industry may exclude the possibility for $\tilde{v}(a, b)$ ever to be positive. Note also that an increase in the inflation rate, $B$, or in the cost of price change, $\beta$, could result in the reduction of $\tilde{v}(a, b)$ to a negative value. 
Note also that there may be many pairs of prices $(a, b)$ consistent with Proposition 2: there need not be a unique price-matching equilibrium.

Consider now a different type of equilibrium, which we shall call the "zero-profit" equilibrium.

Proposition 3: The strategy pair $\left(s_{1}^{*}, s_{2}^{*}\right)$ defined by

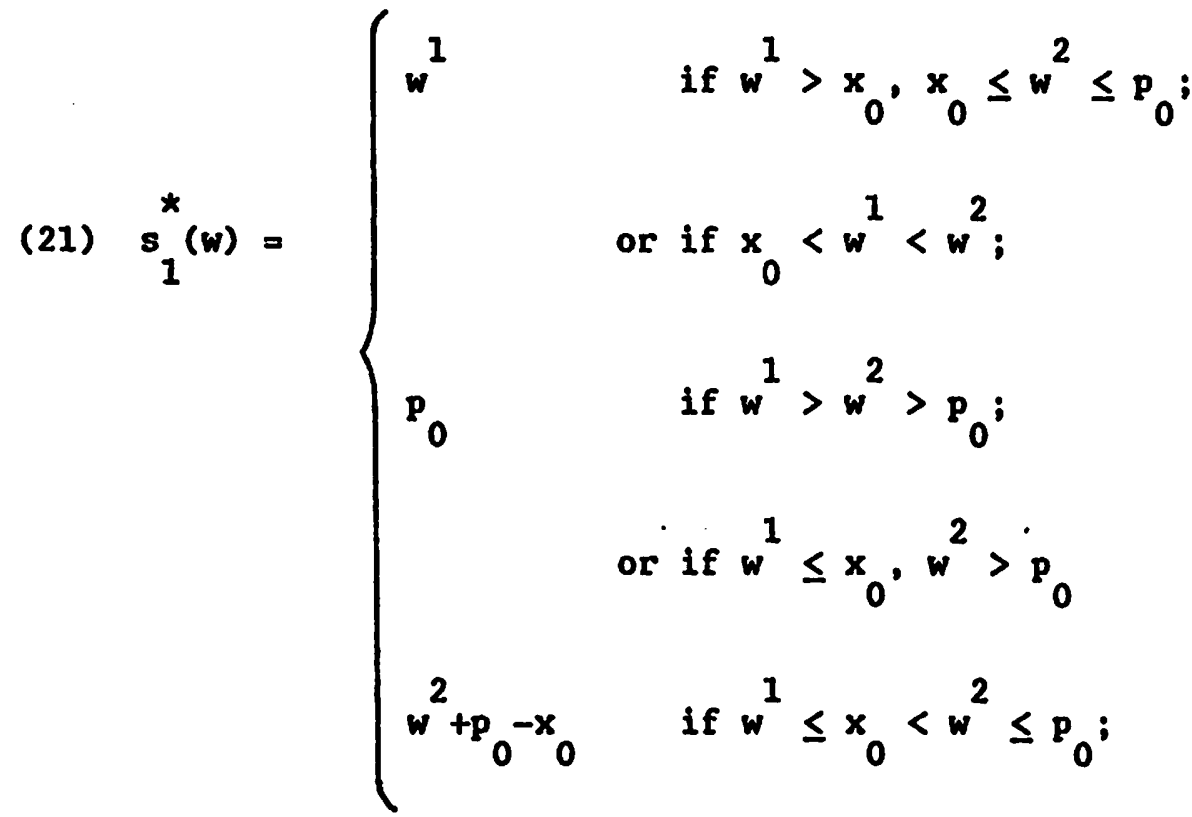

and symetrically $s_{2}^{*}(w)$ defined by $s_{2}^{*}\left(w^{1}, w^{2}\right)=s_{1}^{*}\left(w^{2}, w^{1}\right)$, is an equilibrium. Moreover, no firm can earn positive net discounted profits. A path along which each firm earns zero net discounted profits exists under assumptions 1-7. Proof: Clearly if both firms follow the strategy (21) with the stated initial prices, then, by the definition of $p_{0}$ (following Assumption 5), no firm earns positive discounted profits. We show that if $w^{1}$ is initially equal to $2 p_{0}-x_{0}$ and firm 1 plays the strategy $s_{1}^{*}$, then there exists no interval between price changes where firm 2 earns strictly positive discounted profits net of cost of price change. Note that $s_{1}^{*}$ requires that if firm $1^{\prime} s$ initial real price is $2 p_{0}-x_{0}$, then there does not exist any price path (whatever $s_{2}$ is) 
where firm 1 sets its real price above 2po-xo. If firm 2 sets a price below that of firm 1 but above $P_{0}$ consider a sequence of consistent strategies for firm 1 allowing such a price pair along a path which converge to $s_{1}^{*}$. Then firm 2 would earn positive instantaneous profits for some time $\delta(\delta \rightarrow 0)$, until firm 1 undercuts to $p_{0}$. But as $\delta \rightarrow 0$ these profits would not cover the cost of a price change.

Therefore, if firm 2 is to earn enough profit to pay for its price change, it must start at a price equal to $p_{0}$. Then, after a time interval of $\left(p_{0}-x_{0}\right) / g$, it has earned just enough profits to cover the cost of its next price change. By that time, firm 1 's real price has become equal to $p_{0}$. The best firm 2 can do is earn zero net discounted profits.

$$
\text { Q.E.D. }
$$

Consider a situation in which one firm is changing its price part-way through the other firm's interval of constant nominal price. Consider the lower-priced firm's decision at its time of price change. It can raise its price strictly above its rival's price and, temporarily at least, give up the market to its rival. Alternatively, it can undercut its rival, charging a price slightly less. If undercutting yields positive profit when the cost of the next price change is taken into account, then this is the firm's best action (because it can later raise its price to the alternative, higher price and in the meanwhile it has earned positive, instead of zero, profit). Undercutting is not profitable only if the other firm has set a price yielding zero discounted net profit for itself. If such a price has been set by the other firm, the best this firm can do is raise its price above that and only start earning positive instantaneous profits after its rival in turn increases its price. Thus, an equilibrium requires each firm to increase its price half-way through the other firm's interval of constant nominal price. 
In equilibrium, the lowest-priced firm holds its nominal price until inflation reduces its real price to $x_{0}$; it then increases its real price to $2 p_{0}-x_{0}$. At this point, its rival's real price is $p_{0}$. By the time the rival in turn increases its price, this firm's real price has fallen to $p_{0}$. The time interval between one firm's nominal-price change and the next firm's nominal-price change is $\left(p_{0}-x_{0}\right) / g$. In other words, this path is cyclic in real prices with period length $2\left(p_{0}-x_{0}\right) / g$ for each firm. Each firm's real price at any point in time is $w^{i}=2 p_{0}-x_{0}-g \tau_{i}$ where $\tau_{i}$ represents the time elapsed since $f i r m$ i last changed its nominal price.

The possibility of being undercut by its rival means that, in equilibrium, each firm earns zero net discounted profits. (The equilibrium therefore is reminiscent of the equilibrium of the static price game of Bertrand (1883).)

It is easy to show that adding new firms does not change the time-path of lowest prices. If there were three firms instead of two, then when a firm changed its price it would raise its price to $3 \mathrm{p}_{0}-2 \mathrm{x}_{0}$; it would hold this nominal price until the other two firms had both had an interval of being the lowest-priced seller, by which time its real price would have become $p_{0}$ and it would again be the lowest-priced seller. Thus adding extra firms increases the price the firm sets when it changes its price and increases the interval over which the firm holds its nominal price constant, but does not change the prices at which consumers buy. (Again, this is reminiscent of the Bertrand game: adding extra firms beyond two does not change the equilibrium from the point of view of the buyers.)

The zero-profit equilibrium involves price dispersion: all sellers are charging different prices at any point in time. Hence the staggering of 
price changes provides a novel reason for price dispersion. In this model, prices are dispersed even though all firms are identical, and there is no uncertainty. This contrasts with most explanations of price dispersion, which rely on search costs and differences either among buyers or among sellers.

Suppose that the firms succeeded somehow in colluding. Haximizing joint profits requires that price changes be uniformly staggered. To see this, note that joint profits are

$$
v^{1}+v^{2}=\sum_{\tau=0}^{\infty}\left[\int_{t}^{t} \tau+1\right.
$$

where $t_{T}, t_{T+1}$ are time-points at which one or both of the firms change their nominal prices, $w_{T}$ is the real price immediately following a price change, and $\alpha_{T+1}=1$ (respectively, 2) if only one firm (respectively, both firms) change nominal price at time $t_{\tau+1}$. It is easy to see that $v^{1}+v^{2}$ is maximized with $\alpha_{\tau}=1$; that is, firms changing nominal price alternately. The time-path of lowest prices is as described by the monopoly model of Sheshinski and Weiss (1977), except that the firms alternate in having the lowest price.

Note also that this joint-profit-maximizing price path can be supported as a Nash equilibrium (even in the absence of history-dependent strategies). This can be done by having each firm "threaten" to undercut any deviating price to the $p_{0}$ level.

Thus there is a surfeit of Nash equilibria in this model. There can be either simultaneous or uniformly staggered price changes in equilibrium. In the next section, however, we propose a reasonable criterion that allows us to focus on a particular equilibrium.

\section{Robust Equilibrium}

Note first that none of the equilibria described above are subgame 
perfect. (There appears to be no perfect equilibrium in this model.) The lack of subgame perfection arises because each equilibrium strategy requires the possibility of "punishing" deviations from the equilibrium path; and such "punishments" are not in the interest of the "punisher". (This is clearly the case for the price-matching equilibrium defined by $(20)$ and the joint-profitmaximizing equilibrium defined by (22). It is also the case for the zero-profit equilibrium defined by (21), because (21) requires the high-price firm to lower its price below the low-price firm's price in the event that the low-price firm raises its price any time before the prescribed time of price change.)

There is, however, one criterion that is satisfied by the zero-profit equilibrium but not by the price-matching equilibrium or the joint-profitmaximizing equilibrium. This criterion is that the strategies used never require drastic responses to small deviations by another firm: the firms' strategies are not sensitive to. small mistakes by rivals. Although our model does not allow for uncertainty, it seems reasonable to suppose that only equilibria of this sort would survive the introduction of small anounts of uncertainty. 6

Consider a Nash-equilibrium strategy vector $s^{\star}$. Consider two paths $w_{1}(t), w_{2}(t) \in P(T)$, with $w_{1}(0)=w_{2}(0)$. Suppose that $w_{1}(t) \in P_{s^{*}}(T)$ is the equilibrium path up to $T$. Suppose also that $w_{2}(t)$ is consistent with all the components of $s^{*-i}$. Denote by $d^{i}\left(w_{1}(t), w_{2}(t)\right)$ the sum of the distance between the $i^{\text {th }}$ components of the paths in the $L^{1}$ norin and $\left|v^{i}\left(w_{1}(t)\right)-v^{i}\left(w_{2}(t)\right)\right|$. We call the path $w_{1}(t)$ robust if for any $c>0$ and any $j \neq i$ there exists $\delta>0$ such that $d^{j}\left(w_{1}(t), w_{2}(t)\right)<$ c provided $d^{i}\left(w_{1}(t), w_{2}(t)\right)<\delta$. This means 
that sufficiently small deviations from the strategy-consistent path due to the $i^{\text {th }}$ firm either making its price change slightly earlier or later than prescribed, or going to a price that differs by a small amount from that prescribed, does not bring about a strategic response frotn the other firms which is markedly different: neither an extra price change nor a significantly bigger price change.

It is easy to see that the price-matching strategies (20) are not robust. This is because undercutting, however slight, of the joint price b brings about an extra price change ("matching") from the other firm. Thus however small is the deviation by the firm $i$ from the equilibrium path, $d^{j}>\beta$ for the other firms $j \neq i$.

The zero-profit equilibrium is robust: ${ }^{7}$ if one firm changes its price slightly too early or too late, or by silightly too little or too much, it causes only a small change in the other firms' price paths. Only robust equilibria are not destroyed by small miscalculations by the players or small random shocks in the environment. Hence the zero profit equilibrium is more likely to be observed than the other equilibria.

\section{Changes in Parameters}

We restrict attention now to the zero-profit equilibrium, since, unlike the other equilibria, it is robust. (Also, all it requires for existence is Assumptions 1 through 7; as discussed in Section 5, the matching equilibrium requires additional assumptions.)

Consider now the effect on the equilibrium price path of changes in parameters. Denote by $\Delta$ the interval between two consecutive nominal-price changes; from Proposition 3, $\Delta=\left(p_{0}-x_{0}\right) / B$. The interval between a pair of 
nominal-price changes for a particular firm when $k$ firms operate in the market is therefore $\mathrm{k \Delta}$. When a firm increases its nominal price, the difference between its new nominal price and its old nominal price is $\Gamma=k\left(p_{0}-x_{0}\right)$. (Recall that all prices are expressed as logarithms, so that $\Gamma$ represents a ratio of prices.)

It is easy to show (the proofs are omitted) that $\partial \Delta / \partial \beta>0$ and $\partial \Gamma / \partial \beta>0$. Decreasing the real cost of a price change reduces the interval between price changes and reduces the size of the change in real price. The significance of this is that it is sometimes claimed that institutions and customs eventually adapt to continuing infiation; such adaptations would have the effect of reducing the cost of changing price and therefore, according to this model, making prices less sticky.

By simple arithnetic, an increase in the inflation rate must cause more frequent price changes, or bigger price changes, or both. The next proposition shows that, in this model, an increase in inflation both increases the size of nominal price changes and decreases the interval between price changes. We assume here that $F$ is differentiable.

\section{Proposition 4:}

Equilibrium price paths have the property that

$$
\frac{\partial \Gamma}{\partial g}>0
$$

and

(24) $\frac{\partial \Delta}{\partial g}<0$.


Proof: Denote the expression in (2) or (3) for wo $=p_{0}, W T=x_{0}$ by $\varphi(p 0,8)$. Consider $\partial \varphi / \partial p_{0}$; we shall find two expressions for this derivative. First, by direct differentiation of (2) with $T=\left(P_{0}-x_{0}\right) / 8$ we get

(25) $\frac{\partial \varphi}{\partial p_{0}}=\int_{0}^{\left(p_{0}-x_{0}\right) / 8} F^{\prime}\left(p_{0}-g \tau\right) e^{-r \tau} d \tau+\left(F\left(x_{0}\right)+\beta r\right) \frac{1}{8} e^{-r\left(p_{0}-x_{0}\right) / 8}$

On the other hand, (3) is

$$
\varphi\left(p_{0}, g\right)=\left[\frac{1}{g} \int_{x_{0}}^{p_{0}} F(u) e^{r u / g} d u-\beta e^{r x_{0} / g}\right] e^{-r p} / g
$$

Differentiating and noting that $\varphi\left(p_{0}, 8\right)=0$ we obtain

(27) $\frac{\partial \varphi}{\partial p_{0}}=\frac{1}{g} F\left(p_{0}\right) e^{-r p_{0} / g}$

This is positive, since $F\left(p_{0}\right)>0$, thus the right-hand side of (25) is also positive.

Hext, from (26),

(28)

$$
\frac{\partial \varphi}{\partial g}=\frac{{ }_{0}}{g^{2}} \varphi\left(p_{0}, g\right)+e^{-r p_{0} / g} 1-\frac{1}{2} \int_{x_{0}}^{p_{0}} F(u) e^{r u / g} d u
$$

$$
\left.-\frac{r}{3} \int_{x_{0}}^{p_{0}} u F(u) e^{[u / g} d u+\beta e^{r x_{0} / B} \cdot \frac{r \times x_{0}}{g^{2}}\right]
$$

We utilize $\varphi\left(p_{0}, 8\right)=0$ and for the second integral the generalized Hean Value Theorem to obtain from (28) 
(29) $\frac{\partial \varphi}{\partial g}=-e^{-r\left(p_{0}-x_{0}\right) / g} \frac{\beta}{g}\left[1+\frac{1}{g}\left(\tilde{u}-x_{0}\right)\right]$,

where $x_{0}<\tilde{u}<p_{0}$. Thus, by implicit differentiation,

(30) $\begin{aligned} \frac{\partial p_{0}}{\partial g} & =-\frac{\partial \varphi}{\frac{\partial \varphi}{\partial \varphi}}=\frac{\frac{e}{\partial p_{0}} p_{0}^{\left.-x_{0}\right) / g} \frac{\beta}{g}\left[1+\frac{1}{g}\left(u-x_{0}\right)\right]}{\frac{1}{g} F\left(p_{0}\right) e^{-r p_{0} / g}} \\ & =\frac{r x_{0}^{/ g} \beta\left[1+\frac{1}{g}\left(\tilde{u}-x_{0}\right)\right]}{F\left(p_{0}\right)}>0 .\end{aligned}$

Next rewrite $\varphi\left(p_{0}, g\right)=0$ from (2) as

$$
\int_{0} F\left(x_{0}+g(\Delta-t)\right) e^{-r t} d t-\beta e^{-r \Delta}=0
$$

and denote the left-hand side by $\Psi(\Delta, g)$. Then .

$$
\frac{\partial \psi}{\partial \Delta}=F\left(x_{0}\right) e^{-r \Delta}+g \int_{0}^{\Delta} F^{\prime}\left(x_{0}+g(\Delta-t)\right) e^{-r t} d t+r \beta e^{-r \Delta} .
$$

Noticing that (32) is $\mathrm{B}$ times the right-hand side of (25), which in turn equals the expression in (27), we obtain

$$
\frac{\partial \Psi}{\partial \Delta}=F\left(p_{0}\right) e^{-r p / g}>0
$$

Differentiating $\psi$ with respect to $g$,

(34) $\frac{\partial \psi}{\partial g}=\int_{0}^{\Delta}(\Delta-t) F^{\prime}\left(x_{0}+g(\Delta-t)\right) e^{-r t} d t$. 
By the Mean Value Theorem, and utilizing (25) and (27), we get

(35) $\frac{\partial \psi}{\partial g}=\tilde{\alpha} \frac{1}{g} F\left(p_{0}\right) e^{-\Gamma P / g}>0$

with $0<\tilde{a}<\Delta$.

Therefore

(36) $\frac{\partial \Delta}{\partial g}=-\frac{\frac{\partial \psi}{\partial g}}{\frac{\partial \psi}{\partial \Delta}}=-\frac{\tilde{\alpha}}{g}<0$.

Q.E.D.

Contrast this result with the case of monopoly, in which the effect of inflation on the frequency of price changes is indeterminate: Sheshinski and Weiss (1977).

One of the purposes of this paper was to investigate whether the uniformly staggered structure of price changes assumed by Taylor (1980, 1981) could be the outcome of optimizing actions. By showing that there is a robust equilibrium in which price changes are indeed staggered, the model has in one sense provided some microeconomic foundations for macroeconomic models of this kind. But in another sense these macroeconomic models have been undermined. In these models, on the one hand, the length of time for which nominal prices are held constant is fixed. On the other hand, the inflation rate is allowed to change; indeed, Taylor's 1981 paper analyzes the consequences of variations in the inflation rate. According to the present model, however, a change in the inflation rate causes a change in the period of price constancy. Thus 
Taylor, by making the period of nominal-price constancy independent of the inflation rate, assumed away an interaction which may be of significance for macroeconomic policy.

\section{The Welfare Costs of Inflation}

In an equilibrium in which the firms choose to stagger their price changes, there are relative-price distortions and consequent welfare losses even though inflation is fully anticipated. (If price changes were instead simultaneous, relative prices within the industry would not be distorted.) Increasing inflation causes both bigger increases in nominal prices and more frequent nominal-price increases; thus these relative-price distortions are larger the larger is the inflation rate.

The result that, as the inflation rate increases, both the size and the frequency of nominal-price changes increase is consistent with empirical findings that there is a positive relationship between relative-price variability and the rate of inflation (Cukierman (1983)).

By presenting a model in which there is an equilibrium in which firms choose to stagger their price decisions, this paper provides an explanation for a common empirical finding: studies of the determinants of the general price level have found that the current price level is a function of the price level in the past (Eckstein and Fromn, 1968; de Menil, 1974; HeCallum, 1979; Gordon, 1982). This model is very stylized (in that the firms produce identical outputs and have identical cost functions); however, extrapolation from the present analysis suggests an indirect measure of the extent of inflation-induced relative-price distortions within any industry: the extent 
of autocorrelation in industry price indexes. The more sticky are individual firms' prices, and the greater the tendency to stagger price changes, the larger will be this autocorrelation and the larger the relative-price distortions in any particular industry.

The model also identifies another source of welfare losses. Increasing the inflation rate increases the number of times prices are changed within any. interval of time and therefore increases the size of the total transactions costs incurred. In addition, increasing inflation increases the average real price paid by buyers. To see this, note that the real price a firm charges at the point in time when it becomes the lowest-priced firm in $p_{0}$; this, it has already been shown, increases with the inflation rate. The real price a firm charges just before it ceases to be the lowest-price firm is $x_{0}$; this does not change as inflation increases. Thus the average real price charged by the lowest-priced firm increases with the inflation rate. Increasing inflation therefore forces consumers to pay on average a higher real price. Smaller quantities are purchased. Inflation causes an output loss.

\section{Conclusions}

Under the assumptions that the oligopolistic firms produce homogeneous products under constant returns to scale and incur lump-sum costs of changing price, this paper has shown that, in the face of constant inflation, there is an equilibrium in which price changes are uniformly staggered. A decrease in the cost of changing price causes a decrease in the size of price change and the interval between price changes. An increase in the inflation rate increases the size of price change and decreases the interval between price 
changes. Thus increasing inflation increases relative-price distortions and therefore increases welfare losses. Moreover, increasing inflation increases the average real price paid by consumers, causing output losses and therefore further wolfare coste.

Because there is an equilibrium in which the firms choose to stagger their price changes, the model provides some microeconomic foundations for the macroeconomic model of Taylor $(1980,1981)$. However, in the Taylor model, the interval between price changes is fixed, whereas in the present model, firms will vary this interval as the inflation rate changes. This model thus identifies an interaction which is ignored by the Taylor model.

The staggering of price changes results in equilibrium price dispersion. In equilibrium, each firm earns zero discounted profits. Increasing the number of firms in the industry beyond two increases the stickiness of each firm's price. However, increasing the number of firms does not change the time-path of price paid by consumers and therefore has no effect on consumers' welfare. 


\section{Footnotes}

* We thank Peter Howitt, Chantale LaCasse, Preston McAfee, Michael Parkin, Ariel Rubenstein, and Arthur Robson for their perceptive comments. Both authors' research was supported by the social Sciences and Humanities Research Council of Canada.

1For some empirical evidence that firms tend not to adjust their nominal prices instantaneously, see Kawasaki, Kckillan, and Zimmermann (1982).

2 This model, like that of Taylor (1981), is a model of product markets. Fischer's (1977), Phelp's (1978), and Taylor's (1980) models were expressed in terms of labor markets, but similar analyses would apply to product markets as Taylor (1980, pp. 3-4) noted. On price stickiness in product markets, see Kawasaki, Mckillan, and Zimmermann (1982, 1983).

3 Kussa (1977) examined the macroeconomic consequences of two sources of inflationary losses to a firm: the costs of price changes and the losses from not being at the instantaneous maximum-profit point. Parkin (1986) investigated the properties of the output-inflation tradeoff in a model in which price changes are costly and compared the effects of staggered price changes, simultaneous price changes, and flexible (auction) pricing. Calvo (1983) developed a utility-maximizing model with sticky prices and exogenous timing of price changes. Caplin and Spulber (1985) modelled the implications for aggregate inflation of staggered price changes.

${ }^{4}$ stigler (1947) suggested that costs of changing price might prevent frequent price changes. Costs of changing price as a source of price inflexibility have been modelled, in addition to Sheshinski and Weiss (1977), by Barro (1972), Bewley (1975), Caplin and Spulber (1985), Mussa (1977, 1981), Rotemberg (1982a, 1982b), Kuran (1983), and Parkin (1986). 


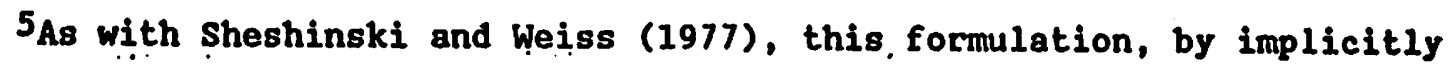
assuming that buyers' demands depend only on current real prices, requires that buyers do not engage in intertemporal substitution in consumption; nor can they store the comnodity.

${ }^{6}$ On the timing of price changes under uncertainty for the case of monopoly, see Danziger (1983) and Sheshinski and Weiss (1983).

It is not hard to show that a robust equilibrium requires non-simultaneous price changes by firms and in addition does not allow for a unilateral price change until the firm's price has hit $x_{0}$. Among robust myopic equilibria those which allow for positive profits are characterized by the following feature: for a firm $i$ an alternative strategy which provides the same value for its payoff functional $V$ always exists; however, employing this strategy will undermine the payoffs of the other firms. Thus a firm is indifferent between two responses to the actions of the other firms and could choose the equilibrium play out of "altruism" or could unilaterally undermine the equilibrium if it were "vicious". This possibility is eliminated in the zero-profit equilibrium: any alternative moves would hurt the deviating firm. 
References

Anderson, Robert H. "Quick-Response Equilibrium," mimeo, University of California, Berkeley, February 1985.

Barro, Robert J. "A Theory of Monopolistic Price Adjustment." Rev. Econ. Studies 39 (January 1972): 17-26.

Bertrand, Joseph. Review of Recherches sur les Principes Mathematiques

de la Theorie des Richesses by Augustin Cournot. Journal des Savants (September 1883): 499-508.

Bewley, T. "A Theoretical Study of Optimal Price Adjustment." Discussion Paper No. 403. Harvard Institute of Economic Research, 1975.

Blanchard, Olivier J. "Price Desynchronization and Price Level Inertia." Discussion Paper No. 899. Harvard Institute of Economic Research, April 1982.

Calvo, Guillermo A. "Staggered Prices in a Utility-Maximizing Framework." Journal of Monetary Economics 12 (September 1983): 383-398.

Caplin, Andrew, and Spulber, Daniel F. "Inflation, Menu Costs, and Endogenous Price Variability," MRG Working Paper No. M8517, University of Southern California, September 1985.

Cukierman, Alex. "Relative Price Variability and Inflation: A Survey and Further Results." Carnegie-Rochester Conference Series on Public Policy 19 (1983): 103-157.

Cyert, Richard $\mathrm{H}$ and de Groot, Morris. "Multiperiod Decision Models with Alternating Choice as a Solution to the Duopoly Problem." Q.J.E. 84 (August 1970): 410-429.

Danziger, Leif. "Price Adjustments with Stochastic Inflation" International Economic Review 24 (Oct. 1983): 699-708. 
de Menil, George. "Aggregate Price Dynamics." Rev. Econ. and Statis. 56

(Kay 1974): 129-40.

Eckstein, Otto and From, Gary. "The Price Equation." A.E.R. 58

(December 1968): 1159-1183.

Fischer, Stanley. "Long-Term Contracts, Rational Expectations, and

the Optimal Honey Supply Rule." J.P.E. 85 (February 1977): 191-206.

Friedman, James W. Oligopoly and the Theory of Games. Amsterdam:

North Holland Publishing Co., 1977.

Fudenberg, Drew, and Tirole, Jean. Dynamic Models of Oligopoly. New York: Harwood, 1986.

Gordon, Robert J. "Price Inertia and Policy Ineffectiveness in the United States, 1890-1980." J.P.E. 90 (December 1982): 1087-1117.

Hussey, D.B. Inflation and Business Policy. New York: Longman, 1976.

Kawasaki, Seiichi, Kckillan, John and Zimmermann, Klaus F. "Disequilibrium Dynamics: An Empirical Study." A.E.R. 72 (December 1982): 992-1004. - "Inventories and Price Inflexibility." Econometrica

51 (Hay 1983): 559-610.

Kuran, Timur. "Asymetric Price Rigidity and Inflationary Bias." A.E.R. 73 (June 1983): 373-82.

Laidler, David. "The Welfare costs of Inflation in Neoclassical Theory Some Unsettled Problems." In Inflation Theory and Anti-Inflation Policy, edited by E. Lundberg. London: Macmillan, 1978.

Lucss, Robert E. Jr. "Tobin and Monetarism: A Review Article." J. Econ. Literature 19 (June 1981): 558-67.

Maskin, Eric and Tirole, Jean. "A Theory of Dynamic 0ligopoly, I: Overview and Quantity Competition with Large Fixed Costs." Mimeo, Massachusetts Insitute of Technology, November 1982.. 
McCallum, Bennett T. "Monetarism, Rational Expectations, 0ligopolistic Pricing, and the MPS Econometric Moel." J.P.E. 87 (February 1979): 57-74.

Mckillan, John and Morgan, Peter. "Price Dispersion, Price Flexibility, and Consumer Search." mimeo. University of Western Ontario, 1986. Uussa, Michael. "The Welfare Cost of Inflation and the Role of Money as a Unit of Account." Journal of Honey, Credit and Banking 9 (May 1977): 278-286 .

- "sticky Prices and Disequilibrium Adjustment in a

Rational Hodel of the Inflationary Process." A.E.R. 71 (December 1981): 1020-1027.

Parkin, Michael. "The Output-Inflation Tradeoff When Price are Costly to Change," Journal of Political Economy 94 (Feb. 1986): 200-224.

Parkin, Michael, and Swoboda, Alexander. "Inflation: A Review of the Issues." In Inflation Theory and Anti-Inflation Policy, edited by $\mathrm{E}$. Lundberg. London: Macmillan 1978.

Phelps, Edmund S. "Disinflation Without Recession: Adaptive Guideposts and Monetary Policy." Weltwirtschaftliches Archiv 114 (December 1978): 783-809. Reprinted as Ch. 11 in his studies in Macroeconomic Theory, V01. 1, Employment and Inflation. New York: Academic Press, 1979. Rotemberg, Julio J. "Konopolistic Price Adjustment and Aggregate Output." Rev. Econ. Studies 49 (October 1982a): 517-532. - "Sticky Prices in the United States." J.P.E. 90 (December 1982b): 1187-1121. 
Sheshinski,"Eytan and Weiss, Yoram. "Inflation and Costs of Price

Adjustment." Rev. Econ. Studies 44 (June 1977): 287-304.

Sheshinski, Eytan, and Weiss, Yoram. "Optimum Pricing Policy under Stochastic Inflation," Review of Economic Studies 50 (July 1983): 513-30.

Stigler, George J. "The Kinky Oligopoly Demand Curve and Rigid Prices." J.P.E. 40 (October 1947): 432-449.

Stiglitz, Joseph E. "Equilibrium in Product Karkets with Imperfect

Information." American Economic Review: Papers and Proceedings 69 (Hay 1979): $339-345$.

Taylor, John B. "Aggregate Dynamics and Staggered Contracts." J.P.E. 88 (February 1980): 1-23. - "On the Relation Between the Variability of Inflation and the Average Inflation Rate." Carnegie-Rochester Conference Series on Public Policy 15 (1982): 57-86. 